\title{
"ESTAR ENTRE": MEDIAÇÃO CULTURAL E EXTENSÃO UNIVERSITÁRIA EM UM FESTIVAL DE ARTES INTEGRADAS
}

\author{
Paulo Cezar Nunes Junior \\ Universidade Federal de Itajubá, Itajubá, Minas Gerais, Brasil \\ Janir Coutinho Batista \\ Universidade Estadual de Campinas, Campinas, São Paulo, Brasil \\ Gabriela Belleze \\ Universidade Federal de Itajubá, Itajubá, Minas Gerais, Brasil
}

\begin{abstract}
Resumo
$\mathrm{O}$ artigo discute o conceito de mediação cultural a partir das experiências advindas com o projeto de extensão universitária intitulado FICA - Festival Integrado de Cultura e Arte. Realizado desde 2011, tal projeto tem por objetivo promover estratégias de democratização cultural e mobilização social, e abrange atualmente nove cidades sul-mineiras. A partir das iniciativas realizadas pela Coordenação de Mediação Cultural observou-se maior engajamento por parte da equipe de trabalho envolvida e público participante, corroborando para apropriações mais significativas da atividades desenvolvidas no festival, sobretudo no que diz respeito ao caráter relacional existente entre intermediadores culturais, públicos expectadores e artistas participantes.
\end{abstract}

Palavras-chave: Cultura. Arte. Extensão Universitária. Atividades Culturais. Mediação Cultural.

\section{Introdução}

Na Praça Central, dezenas de crianças se revezam na construção de um grande painel interativo vertical; no pátio da escola municipal, adolescentes participam de uma oficina de graffiti e breakdance; no cabaré noturno, atrações levam para o palco a temática da diversidade sexual; no lar de idosos, senhores e senhoras participam de um baile com as canções guardadas em suas memórias; na sala de aula, alunos do ensino médio preparam textos e charges para um concurso de redação. Estas são algumas das inúmeras cenas que já compuseram a grade de programação do FICA - Festival Integrado de Cultura e Arte, projeto realizado anualmente por uma rede colaborativa de jovens, líderes comunitários, gestores públicos, artistas e produtores culturais em nove cidades na região sul do Estado de Minas Gerais ${ }^{1}$.

\footnotetext{
${ }^{1}$ Em sua última edição, o FICA foi realizado nos municípios de Itajubá, Delfim Moreira, Pedralva, Piranguinho, Piranguçu, Maria da Fé, Gonçalves, Cristina e Brazópolis. Todas estas cidades geralmente tem pouca oferta de agenda cultural permanente e apresentam características sócio-demográficas parecidas: economias de base rural, setor de serviços e parque industrial ainda incipiente, população média de até 20.000 habitantes (com exceção de Itajubá, cuja população total é de 90.000 habitantes).
} 
Trata-se de um festival de artes integradas com programação na área de música, dança teatro, artes visuais, performances e oficinas de formação que tem por objetivo promover estratégias de mobilização social por meio do intercâmbio artístico e cultural nas cidades participantes. A proposta surgiu em 2011 a partir de um projeto de extensão universitária intitulado "Lazer e Espaço Urbano em Itajubá: Diagnóstico e Proposta de Novos Usos", executado pela Universidade Federal de Itajubá e com financiamento do edital interministerial PROEXT MEC SESu - Programa de Extensão Universitária. Originalmente, o projeto previa ações conjugadas com disciplinas de ensino de graduação e frentes de pesquisa ligadas ao campo multidisciplinar, e como ação extensionista era executado dentro de um cronograma que vislumbrava quatro etapas de execução: diagnóstico e mapeamento de espaços de lazer e cultura na cidade; ações junto a grupos e artistas locais; realização de um festival de artes integradas e elaboração de documentos sobre o desdobramento das ações (NUNES JUNIOR, 2012).

Desde então já foram realizadas cinco edições do festival, onde várias ferramentas de trato prático com a extensão universitária na área da cultura puderam ser construídas, traçando novos caminhos para a expansão e consolidação do projeto. O desejo original das ações baseava-se na construção de diálogos com a população e na proposição de novos usos para os espaços públicos urbanos notadamente esvaziados e carentes de uso. Todo o trabalho de engajamento através de oficinas, cursos, espetáculos e demais atividades culturais permitiram uma aproximação do público com as cidades participantes por meio da apropriação dos locais escolhidos para sediar as atividades previstas no projeto.

Nesta mesma direção, o exercício de pensar as novas interfaces do festival com o público expectador ganhou destaque no planejamento das ações, corroborando para a criação de uma área específica de tratamento deste assunto dentro da organização do evento, a qual foi denominada Coordenação de Mediação Cultural. Os objetivos principais desta frente de trabalho dentro da operacionalização do projeto é tornar mais efetivas as ações culturais nas diversas regiões periféricas abrangidas pelo festival, visando a descentralização das atividades, ampliando o acesso à programação e contribuindo na formação de público e capacitação de agentes culturais. A partir destas estratégias, a área da mediação cultural permite aos alunos de graduação, jovens, lideranças comunitárias e agentes locais a possibilidade de engajarem-se em ações de extensão cultural e multidisciplinar, colocando em prática os conhecimentos construídos em âmbito acadêmico. A dinâmica de concepção, da montagem e principalmente da implementação de atividades de mediação cultural pelo festival mostraram-se de grande importância para as cidades envolvidas. As ideias e processos colaborativos vivenciados na condução do projeto junto a jovens, representantes comunitários e outros intermediários culturais acabaram sendo enraizadas e ramificadas entre as diversas lideranças artísticas e instituições culturais da região, demonstrando o poder de retroalimentação que existe na construção de saberes entre a universidade e a sociedade através da extensão universitária.

Buscando avançar com a discussão e tendo por base o caráter eminentemente executivo do festival, não pretendemos tecer aqui apenas um debate sobre mediação cultural que pretenda uma definição específica para seu conceito, menos ainda, fundamentá-la a partir de teorias que poderiam incorrer no distanciamento do exercício de pensar nossa prática com o projeto. Nossa estratégia é outra: trata-se de construir uma noção de mediação cultural por meio das experiências vivenciadas nas três últimas edições do Festival Integrado de Cultura e Arte (FICA) a partir de sua dimensão prática e relacional. Contudo, antes disso é preciso resgatar a forma pela qual o conceito vem sendo tratado pelos pesquisadores da área, para então percebermos o modo como ele adquiriu corpo em nosso projeto, potencializando a participação do público e tornando mais efetiva a apropriação das atividades da programação do festival. 
Estes são os motivos que nos levam a escrever este texto. Partimos deles para estabelecer o objetivo principal deste artigo: relatar os processos de mediação cultural vivenciados no Festival Integrado de Cultura e Arte durante as edições de 2013, 2014 e 2015. Com isso, esperamos contribuir para o debate em torno da cultura e das possibilidades de atuação da extensão universitária dentro deste campo.

\section{A mediação cultural e seu caráter relacional}

No seu sentido mais tradicional, o conceito de mediação cultural está diretamente ligado à relação do público com a instituição cultural promotora do evento ou do projeto, do artista com o expectador, do curador com a curadoria educativa, do museógrafo e do desenho museográfico e da exposição com os visitantes (MARTINS, 2012). Além disso, estão cada vez mais recorrentes em instituições e eventos culturais a associação deste conceito com os mecanismos que facilitam o acesso de pessoas com deficiência à programações e eventos artísticos em geral. Atualmente as discussões sobre este assunto são cada vez mais comuns em núcleos artísticos, congressos temáticos e políticas culturais setoriais, espaços onde podem ser observados esforços para a criação de novas formas de proximidade do público com as ações culturais. Neles, uma série de novas iniciativas investigam a relação mais direta entre o público e o artista, de onde advém conceitos como residência artística (LA FORTUNE, 2012), audience-as-artist (HARLOW, 2014), co-creation, crow sourcing, educational enrichment (KOSTER, 2008), cultura e desenvolvimento local (SELLAS \& COLOMER, 2009) entre outros.

No caso do Brasil, o debate em torno deste campo foi levado a cabo notadamente a partir da década de 1990. Até esta época, quando ainda eram incipientes temas como acessibilidade e curadoria educativa, observam-se iniciativas mais isoladas sobre o assunto, em sua maioria na cidade de São Paulo e alguns outros grandes centros do país. Desde então os trabalhos acadêmicos sobre mediação cultural muitas das vezes aparecerem ligados a consultorias e prestação de serviços para grandes exposições, feiras e museus, uma vez que o país precisava capacitar e formar seus agentes culturais para este campo de atuação. Consultando as publicações mais recentes sobre o assunto, é possível perceber uma maior interlocução com novos autores e teorias no campo da filosofia e das ciências humanas, a exemplo dos esforços de Martins (2012) e seu conceito de cartografias da mediação cultural, com base na teoria rizomática de Deleuze e Guattari (1995).

A partir deste novo olhar sobre o campo, a mediação cultural passa a dar maior ênfase na dimensão da ação como relação, do papel do mediador como aquele que busca enxergar e operar potencialidades no campo da arte e da cultura, do espaço onde o educador, o professor, o curador e o espetáculo dialogam e criam uma fecunda rede de relações. Este desenho mais aberto e poroso vai ao encontro da afirmação de Martins (2006) quando diz que a ação de mediar precisa operar "não como ponte entre quem sabe e quem não sabe, entre a obra e o espectador, mas como um 'estar entre' muitos, provocar diálogos, dar acesso" (MARTINS, 2006, p. 11).

De certa forma, este tipo diálogo já havia sido captado por Walter Benjamin no célebre texto A obra de arte da era da reprodutibilidade técnica (BENJAMIN, 1994), quando o autor argumenta sobre o papel da experiência estética: ela coloca o sujeito em um outro lugar, recria a realidade a partir do ponto de referência localizado na relação com a obra de arte. Neste movimento para "um outro lugar", o sujeito passa pelo que chamamos em uma das edições de nosso festival de deslocamento. Deslocar-se, que dentre suas várias conceituações, indica mudar de direção; desviar; e evoca um certo distanciamento, uma desagregação dos sentidos na descoberta de campos outros de visibilidade e horizontes (NUNES JUNIOR, BATISTA, 2012). Assim, quando propomos que as atividades de arte e cultura ocupem 
notadamente o espaço público, estamos desenvolvendo na verdade um deslocamento duplo: do sujeito, que passa a reler a realidade a partir da abordagem do trabalho artístico apresentado; e do espaço, que passa a ser recriado por uma relação até então impensada.

Além de operar a transformação da relação espaço-sujeito, este movimento atua também na relação sujeito-sujeito. Pela ótica do filósofo francês Gilbert Simondon (1989), toda relação é uma relação de transformação, assim, o encontro do sujeito com a arte produz um deslocamento de percepção que o faz modificar. O conceito de transdução utilizado pelo autor nos permite pensar a arte contemporânea, pois o sujeito pode observar uma manifestação artística buscando reconhecer algo já visto ou algo já dito, sucumbindo seu encontro com ela. O que precisa ser potencializado é o "estar entre" e permitir ser tocado nesta interação. Para ele, trata-se de um processo de dar-se conta da natureza da operação do transindividual (SIMONDON, 1989). Simondon deixa de conceber o objeto apenas pelo que ele é, para pensar no que ele pode vir à ser a partir de sua relação com o meio.

Em A individuação psíquica e coletiva, o autor fala deste além-arte, que pode ser interpretado como um indivíduo resultante de um processo dinâmico - "o indivíduo vivente é sistema de individuação, sistema individuante e sistema que se individua" (SIMONDON, 1958). Isso permite situar a reflexão nas fronteiras em que a atualidade pressiona os limites da experimentação moderna, esperando o salto, a transmutação da arte e uma imagem outra de vida. (BATISTA, NUNES JUNIOR 2012). Simondon pode ainda iluminar o debate em torno do tema da mediação cultural quando escreve sobre uma possível experiência do excesso a partir da transindividualidade (SIMONDON, 1989), do "ser vivo e mais do que vivo" (SIMONDON, 2009), ser ao mesmo tempo indivíduo e mais do que indivíduo buscando provar algo que transborda seu ser individuado.

Entendemos ser este o papel da experiência estética e dos deslocamentos vivenciados com os projetos culturais: a obra de arte, a experiência com o espaço-tempo do espetáculo se mostra como potência, como núcleo que guarda uma série de possibilidades e de coisas não ditas. Para Deleuze (1995) estas são as linhas que nos fazem escapar, traçar trajetórias que produzem novos modos de percepção. Fazem com que o sujeito exceda seu ser individuado, ansiando por um movimento de liberdade que contém e está contido na sua rotina comum, nas suas ações de apropriação e de transformação da realidade. Pela possibilidade desse outro olhar, da construção de uma ação artístico-política renovada e de uma mediação cultural transformadora é que o FICA encontrou na região sul do estado de Minas Gerais, a fertilidade necessária para concretizar-se, escolhendo como objetivo paralelo à revitalização da própria cultura sul-mineira e da interconexão com as diversas culturas do Brasil.

\section{Nossos encontros e a condição de "estar entre"}

O "estar entre" elucidado por Miriam Martins (2006) talvez seja o ponto definidor do FICA, e exatamente o que o aproxima de sua ação com a extensão, uma vez que a universidade deve auxiliar no desenvolvimento de políticas e programas diretamente relacionados com as demandas da sociedade. Para endossar esta ideia, apresentamos a definição de extensão universitária presente no documento criado pelo Fórum de Pró-Reitores de Extensão das Universidades Públicas Brasileiras em 2001, o qual diz que: "A Extensão Universitária é um processo educativo, cultural e científico que articula o Ensino e a Pesquisa de forma indissociável e viabiliza a relação transformadora entre Universidade e Sociedade." (FÓRUM DE PRÓ-REITORES DE EXTENSÃO DAS UNIVERSIDADES PÚBLICAS BRASILEIRAS, 2001). Trata-se de uma via de mão-dupla, com trânsito assegurado à comunidade acadêmica, que encontrará, na sociedade, a oportunidade de elaboração da práxis de um conhecimento acadêmico. No retorno à universidade, docentes e discentes envolvidos trarão um aprendizado que, submetido à reflexão teórica, será acrescido àquele conhecimento. 
Neste sentido, o FICA precisou levar em consideração possibilidades de construção e formas de ação cultural diferentes daquelas convencionalmente adotadas pelo mercado cultural e pelos eventos de entretenimento. O olhar na produção e na distribuição de conhecimento pela universidade e o caráter multiplicador do projeto junto às lideranças comunitárias e jovens das cidades participantes acabou gerando um escopo de trabalho bastante interessante para o modelo de extensão universitária acima enunciado e, conforme aponta Simondon (1989), com foco no processo, e não no produto.

É importante relatar que até aqui o FICA contou com o apoio de uma equipe bastante numerosa, com 65 pessoas diretamente envolvidas na coordenação do evento e 205 jovens capacitados em cursos de extensão em produção cultural oferecidos pela universidade. Como consequência deste movimento, o engajamento e a participação ativa destes jovens universitários e lideranças comunitárias possibilitam experiências práticas significativas, de exceção, como diria Simondon (1989), fornecendo subsídios e vivências sociais importantes para a formação e futura atuação, política e profissional de cada um deles.

A oferta de atividades dentro da grade de programação do FICA foi pensada para a criação de encontros inusitados entre arte e público. Por tratar-se de cidades de pequeno porte e, como tantas outras, com pouco acesso a eventos e projetos artístico-culturais de qualidade, foram necessárias estratégias de mobilização que aproximassem a plateia do espetáculo: palcos em rotatórias de trânsito, shows em terminais rodoviários, mostras em saguões de bibliotecas, intervenções em parques e outros locais de circulação cotidiana; soluções criativas que proporcionassem contato direto com as atividades da programação a partir da ativação de espaços a princípio com usos pouco prováveis para esta finalidade. $\mathrm{O}$ festival acabou deslocando-se até o público, tornando visível e dando existência para diversas práticas e sensações não ditas, para a poesia de varais, para o circo na praça, para cada um dos jovens voluntários que, de forma quase despercebida, se convertia em agente cultural da cidade "encontrando ecos possíveis a serem despertados" (MARTINS, 2001).

Todos estes exemplos ilustram a necessidade do encontro defendida por Simondon (1989), uma vez que a partir dele são possíveis inúmeras estratégias de transformação. No processo de mediar estes encontros, é preciso conhecer cada um desses interlocutores:

[...] estar atentos às falas, aos silêncios, às trocas de olhares, ao que é desvelado e velado, aos conceitos e repertórios que ditam os gostos, os modos de pensar, perceber e deixar-se ou não envolver pelo contato, com a experiência de conviver com a arte e o seu desafio maior: provocar uma experiência estética (MARTINS, 2006, p.11).

Com o desenvolvimento do FICA, as ações de mediação cultural ficaram cada vez mais claras com relação à forma de organizar e distribuir as funções referentes a este campo de atuação. A esta altura, é preciso deixar claro uma vez mais que falar da mediação cultural não é definir um modo do que ver e como ver, como uma espécie de "pedagogia estética", mas sim descrever um processo na ordem dos encontros e de diálogos que permitem um deslocamento de percepções daqueles que participam deste processo. Nas ações práticas dentro do FICA, a Coordenação de Mediação Cultural tem o intuito de aproximar as manifestações artísticas do universo cultural das cidades, ampliando o acesso e a fruição dos espetáculos, shows, oficinas e mostras por parte de toda a população de acordo com os princípio da democratização cultual (PRATT, 2015). Além disso, conta com uma agenda de atividades e ações em lares de idosos, oficinas de arte em escolas públicas, debates sobre diversidade sexual, caravanas rurais, curso de formação para produtores voluntários, diálogo com associações de catadores para coleta de materiais recicláveis durante o evento, fomento e valorização da culinária local vinculada à produção de camarins, entre outros. 
Esta Coordenação tem ainda a incumbência de desenvolver ações que permitem a participação de pessoas com deficiência nas atividades do projeto e, além disso, pensa e desenvolve ações de sustentabilidade em todas as etapas de execução: pré-produção, produção e pós-produção dos evento. Pelo aspecto formativo praticado junto aos produtores voluntários envolvidos, o festival se desenvolve cada vez mais preocupado com ações perenes, que gerem novas iniciativas, formação de público, e que principalmente despertem o movimento da transindividualidade defendida por Simondon (1989).

\section{Considerações finais}

Passadas quatro edições de organização e planejamento de ações extensionistas a partir da produção do festival, notamos que o tema da mediação cultural tem ainda um vasto campo a ser percorrido em termos de ferramentas práticas de trabalho que sejam efetivas e transformadoras na relação do sujeito com a ação cultural. Se por um lado as publicações e experiências compartilhadas auxiliam nossa prática como educadores e agentes culturais; por outro as demandas advindas por parte do público e as limitações enfrentadas na escolha e na oferta das atividades durante o FICA nos mostram que é necessário caminhar ainda mais. É preciso ter olhar atento na dinâmica contida no lugar de atuação e na forma com que o sujeito se apropria da proposta oferecida; porém sem deixar de lado o caráter de antecipação contido na arte. De alguma forma, sua aura (BENJAMIN, 1994) deve sempre ser mantida para que possa lançar sobre a realidade a potência necessária para transformá-la.

Antes de encerrar, achamos pertinente ainda compartilhar pontos que reconhecemos ser de grande importância para a manutenção do caráter colaborativo e participativo que define o FICA como um projeto de extensão universitária, sobretudo tendo em vista a maior participação de estudantes de graduação. Algumas simples ações podem alavancar a participação destes jovens, tais como a necessidade de sincronizar o cronograma de ações do evento com o calendário de atividades acadêmicas (a ideia aqui é fazer com que períodos com grande demanda de produção do festival não coincidam com semanas de provas da universidade, seminários, laboratório, entre outros), o registro da ação nas Pró-Reitorias de Extensão ou órgãos equivalentes (para comprovação de carga horária em atividades complementares) e o convite à publicação de trabalhos e participação em eventos técnicos e científicos que se relacionem com o tema.

Embora a participação em todo o processo de criação do festival pressuponha o trabalho voluntário, outro ponto que pode ser definidor para o sucesso do projeto é a possibilidade de bolsas de extensão ou qualquer outro tipo de auxílio alunos universitários envolvidos. No caso de jovens e pessoas sem vínculo com a universidade, será preciso checar formas de remuneração via estágios ou outros editais específicos, em sintonia com colaboradores locais e com o envolvimento da comunidade.

A condição do "estar entre" exigido pela mediação cultural (MARTINS, 2006) exige também que seja mantido um diálogo constante com outros setores da universidade e da sociedade como um todo. Neste sentido, a participação do poder público é imprescindível para que seja instituída uma agenda de políticas culturais de forma mais perene. É necessário promover um debate que crie aproximações com a prefeitura, com o conselho municipal de cultura, com associações de bairro e outros coletivos locais existentes para ampliação da participação popular. Nossas experiências nos mostraram que o trabalho de um mediador cultural pressupõe sobretudo o exercício de saber transitar, articular e produzir pensamento sobre e através da prática. Neste sentido, a mediação cultural é ainda um campo aberto a constantes reinvenções, uma vez que está inscrita nas experiências e encontros com todos aqueles que compartilham destas e de outras inúmeras ações que ocorrem diariamente neste vasto campo de atuação cultural. 


\title{
" BE BETWEEN" : CULTURAL MEDIATION AND UNIVERSITY EXTENSION IN AN INTEGRATED ARTS FESTIVAL
}

\begin{abstract}
This paper discuss the concept of cultural mediation based on data collected from the University Extension Program, well know as FICA - Festival Integrado de Cultura e Arte. Held since 2011, it is a Sort of event, that take place in within nine cities located in the south of Minas Gerais State. The aim of this project rests on both, democratic and mobilizes cultural strategies. From the initiatives undertaken by the Cultural Mediation Coordination we noticed a growing number of people that is engaged to realize this, particularly, the work team and the audience who expressed a pure appropriation of the activities during the festival, specially the relationship established among the work team, the audience and artists.
\end{abstract}

Keywords: Culture. Arts. Extension University. Cultural Activities. Cultural Mediation.

\section{"ESTAR ENTRE": MEDIACIÓN CULTURAL Y EXTENSIÓN UNIVERSITÁRIA EN UN FESTIVAL DE ARTES INTEGRADAS}

\begin{abstract}
Resumen
El artículo discute el concepto de mediación cultural a partir de la experiencia resultante de la realización del proyecto de extensión universitaria titulado FICA - Festival Integrado de Cultura y Arte. Realizado desde 2011, este proyecto busca promover las estrategias de democratización cultural y movilización social en nueve ciudades del sur del estado de Minas Gerais. A partir de las iniciativas emprendidas por la Coordinación de Mediación Cultural, se observó un mayor compromiso por parte del equipo de trabajo involucrado y del público participante, resultando apropiaciones más significativas de las actividades en el festival, sobre todo en lo que respecta el carácter relacional existente entre los intermediarios culturales, públicos y artistas participantes.
\end{abstract}

Palabras clave: Cultura. Arte. Extensión Universitaria. Actividades Culturales. Mediación Cultural.

\section{Referências}

BENJAMIN, Walter. A obra de arte na era de sua reprodutibilidade técnica. In: BENJAMIN, Walter. Magia e Técnica: ensaios sobre literatura e história da cultura. Tradução de Sergio Paulo Rouanet. São Paulo: Brasiliense, 1994. p. 165 - 196.

DELEUZE, Gilles. GUATTARI, Félix. Introdução: Rizoma. In.: Mil Platôs - capitalismo e esquizofrenia. Rio de Janeiro: Ed: 34, Vol.1, 1995.

FÓRUM DE PRÓ-REITORES DE EXTENSÃO DAS UNIVERSIDADES PÚBLICAS BRASILEIRAS. Avaliação da Extensão Universitária. Brasília: MEC/SESu; Ilhéus: Editus, 2001. (Coleção Extensão Universitária; v.3).

HARLOW, Bob. The road to the results effective practices for building arts audiences. Wallace Foundation, 2014. Disponível em: <http://www.wallacefoundation.org/>. Acesso em 09/mar./2016. 
LA FORTUNE, Jean-Marie. La médiation culturelle: Le sens des mots et l'essence des pratiques". Québec: Les Presses de l'Université du Québec, 2012.

KOSTER, Pau Rausell et alli. Cultura: estrategia para el desarrollo local. Agencia Española de Cooperación Internacional, AECID, 2008.

MARTINS, Mirian Celeste. Acolhimento estético: mediação para públicos especiais na Mostra Redescobrimento em São Paulo. Revista de Educação PUC-Campinas. Campinas, n. 11, Nov. 2001, p.100-104.

MARTINS, Mirian Celeste (Coord.). Curadoria educativa: inventando conversas. Reflexão e Ação - Revista do Departamento de Educação/UNISC. Universidade de Santa Cruz do Sul,vol. 14, n.1, jan/jun 2006, p.9-27.

MARTINS, Miriam Celeste (Coord.). Mediação cultural: Expandindo conceitos entre territórios de arte \& cultura. Universidade Presbiteriana Mackenzie, 2012. Disponível em: http://www.faeb.com.br/livro/Comunicacoes/mediacao\%20cultural\%20expandindo\%20conce itos.pdf. Acesso em 10 mar. 2014.

NUNES JUNIOR, Paulo Cezar. 2012. Dados e Relatos de Lazer em Itajubá (MG) a Partir da Experiência de um Projeto de Extensão Universitária. In: XIII Seminário O Lazer em Debate, 2012, Belo Horizonte. Coletânea de textos XIII Seminário O Lazer em Debate.

NUNES JUNIOR, Paulo Cezar. BATISTA, Andressa Coutinho. 2012. Proposta Curatorial FICA 2012. Disponível em: http://www.ficaitajuba.com.br/2012/o-festival/proposta. Acesso em: 19/mar./13.

PRATT, Andy C. Cultural Industry and Publicy Policy, an axymoron?. International Journal of Cultural Policy, V. 11, N. 1, 2015.

SELLAS, Jordi \& COLOMER, Jaume. Marketing de las artes escénicas. Creación y desarrollo de públicos. Barcelona: Cuadernos Gescénic, 2009.

SIMONDON, Gilbert. La individuación. A La luz de las nociones de forma y información. Tradução: Pablo Ires. Buenos Aires: Ediciones La Cebra y Editorial Cactus, 2009.

L’individuación psychique et collective. À la lumiére des notions de Forme, Information, Potentiel et Métastabilité. Paris: Aubier, 1989.

Du mode d'existence des objets techniques. Paris: Aubier, 1958.

Recebido em: 15/03/2016

Revisado em: 10/08/2016

Aprovado em: 05/09/2016

Endereço para correspondência:

paulonunes@unifei.edu.br

Paulo Cezar Nunes Junior

Universidade Federal de Itajubá, Instituto de Ciências.

Avenida BPS, 1303 
Pinheirinho

37500903 - Itajubá, MG - Brasil

Caixa-postal: 050 